\title{
Patients undergoing colorectal cancer screening underestimate their cancer risk and delay presentation for screening
}

\author{
Haili Wang MD, Nicholas Gies BScKin, Clarence Wong MD, Dan Sadowski MD, \\ Barbara Moysey RN BSN, Richard N Fedorak MD
}

H Wang, N Gies, C Wong, D Sadowski, B Moysey, RN Fedorak. Patients undergoing colorectal cancer screening underestimate their cancer risk and delay presentation for screening. Can J Gastroenterol 2012;26(7):419-423.

BACKGROUND: Colorectal cancer (CRC) is the third most common cancer in Canada. Screening guidelines recommend that first-time screening should occur at 50 years of age for average-risk individuals and at 40 years of age for those with a family history of CRC.

OBJECTIVE: To examine whether persons with a positive CRC family history were achieving screening at 40 years of age and whether average-risk persons were achieving screening at 50 years of age.

METHODS: The present study was a cross-sectional analysis of subjects who entered a colon cancer screening program and were undergoing CRC screening for the first time.

RESULTS: A total of 778 individuals were enrolled in the present study: 340 (174 males) with no family history of CRC, and 438 (189 males) with a positive family history of CRC. For the group with a positive family history, the mean $( \pm$ SD) age for primary screening was $54.4 \pm 8.5$ years, compared with $58.2 \pm 6.4$ years for the group with no family history. On average, those with a positive family history initiated screening 3.8 years $(95 \%$ CI 2.8 to $4.8 ; \mathrm{P}<0.05)$ earlier than those without. Adenoma polyp detection rate for the positive family history group was $20.8 \%(n=91)$ compared with $23.5 \%(n=80)$ for the group with no family history.

CONCLUSIONS: Individuals with a positive CRC family history are initiating screening approximately four years earlier than those without a family history; nevertheless, both groups are undergoing screening well past current guideline recommendations.

Key Words: Adenoma; Colonoscopy; Colorectal cancer; Family history; Polyp; Screening

Oolorectal cancer (CRC) is a major public health concern. It is the third most common cancer and the second-ranked cause of cancer-related death in Canada. The Canadian Cancer Society estimated that there were 22,500 Canadians diagnosed with CRC in 2010 and 9100 died from it (1).

In 2010, the National Cancer Institute estimated that there were 102,900 new cases of colon cancer, 39,670 new cases of rectal cancer and 51,370 combined colon and rectal cancer deaths in the United States (2).

Nevertheless, CRC can be curable if identified early and preventable if found through screening at the precancerous adenomatous polyp stage. A family history of CRC is currently the most important risk factor for predicting CRC (3). The lifetime probability of CRC for an average-risk person is $6 \%$, whereas if an individual has a first-degree relative with CRC, there is a two- to threefold fold increase in risk. Current North American screening guidelines recommend starting

\section{Les patients qui subissent un dépistage de cancer colorectal sous-estiment leur risque de cancer et retardent leur rendez-vous}

HISTORIQUE : Le cancer colorectal (CCR) est le troisième cancer en importance au Canada. Selon les lignes directrices de dépistage, le premier examen est recommandé à 50 ans chez les personnes affichant un risque moyen et à 40 ans chez celles qui ont des antécédents familiaux de CCR.

OBJECTIF : Examiner si les personnes ayant des antécédents familiaux de CCR subissaient un dépistage à 40 ans et si celles ayant un risque moyen le subissaient à 50 ans.

MÉTHODOLOGIE : Analyse transversale des sujets qui participaient à un programme de dépistage du CCR pour la première fois.

RÉSULTATS : Au total, 778 personnes ont participé à la présente étude, soit 340 sujets (174 hommes) sans antécédents familiaux de CCR et 438 sujets ( 189 hommes) ayant des antécédents familiaux de CCR. Le groupe ayant des antécédents familiaux a subi le dépistage primaire à un âge moyen $( \pm E ́ T)$ de $54,4 \pm 8,5$ ans, par rapport à $58,2 \pm 6,4$ ans dans celui sans antécédents familiaux. En moyenne, ceux qui avaient des antécédents familiaux amorçaient le dépistage 3,8 ans (95 \% IC 2,8 à 4,8; $\mathrm{P}<0,05)$ plus tôt que les autres. Le taux de détection de polypes adénomateux dans le groupe ayant des antécédents familiaux s'élevait à 20,8\% $(n=91)$, par rapport à 23,5\% $(n=80)$ dans le groupe sans antécédents familiaux.

CONCLUSIONS : Les personnes ayant des antécédents familiaux de CCR amorcent le dépistage environ quatre ans avant celles sans antécédents familiaux, mais les deux groupes subissent ce dépistage très longtemps après le moment recommandé dans les lignes directrices à jour.

CRC screening at 50 years of age for an average-risk individual, and at 40 years of age or 10 years earlier than the youngest diagnosis in the family, whichever comes first, for those with family history of CRC or adenomatous polyps (4).

The methods of population-based CRC screening recommended by multiple societies and foundations consist of one or a combination of the following: fecal occult blood testing, flexible sigmoidoscopy, aircontrast barium enema, computed tomography-colonography and colonoscopy, with colonoscopy being used for confirmation and removal of detected adenomatous polyps $(5,6)$. It is important to note that these population-based screening guidelines do not apply to subjects with a family history of genetic CRC syndromes or those with inflammatory bowel disease because these individuals would be at even higher risk for $\mathrm{CRC}$ and, thus, have separate screening guidelines (7).

A survey of more than 6800 individuals in the United States demonstrated that those with a strong and intermediate family history of

Division of Gastroenterology, University of Alberta, Edmonton, Alberta

Correspondence: Dr Richard N Fedorak, Division of Gastroenterology, University of Alberta, Zeidler Ledcor Centre, Edmonton, Alberta T6G 2X8

Telephone 780-492-6941, fax 780-492-8121, e-mail richard.fedorak@ualberta.ca

Received for publication August 12, 2011. Accepted December 5, 2011 
TABLE 1

\section{Subject demographics}

\begin{tabular}{|c|c|c|}
\hline & \multicolumn{2}{|c|}{ Family history of CRC } \\
\hline & Negative $(n=340)$ & Positive* $(n=438)$ \\
\hline Male, n (\%) & $174(51.2)$ & $189(43.1)$ \\
\hline Female, n (\%) & $166(48.8)$ & $249(56.9)$ \\
\hline $\begin{array}{l}\text { Age at first CRC screening }{ }^{\dagger} \text {, } \\
\text { years, mean } \pm S D\end{array}$ & $58.2 \pm 6.4$ & $54.4 \pm 8.5$ \\
\hline Adenoma polyp detection rate, $\%$ & 23.5 & 20.8 \\
\hline \multicolumn{3}{|c|}{$\begin{array}{l}\text { *Positive family history of colorectal cancer }(C R C)=\text { one first-degree relative } \\
\text { with CRC and/or histologically proven adenomatous polyp, or two second- } \\
\text { degree relatives with CRC; }{ }^{\dagger} \text { Refers to any CRC screening initiated by their } \\
\text { physicians outside of the Stop COlorectal cancer through Prevention and } \\
\text { Education (SCOPE) Pilot program }\end{array}$} \\
\hline
\end{tabular}

CRC, only $45 \%$ and $23 \%$ had undergone appropriate CRC screening, respectively. In fact, more than $50 \%$ of these groups did not even know that they should be screened at a younger age than average-risk people (8). Subjects' lack of awareness of CRC screening guidelines could be attributed, in part, to knowledge transfer from physicians and health care providers. Only 39\% of the respondents younger than 50 years of age reported that their health care provider had ever asked them if there was a family history of CRC or informed them of the increased risks (8). Despite these less than optimal numbers, the literature has demonstrated that individuals at increased risk of CRC are more adherent to screening programs than average-risk individuals (3).

In the present study, we questioned individuals with no family history of CRC (average risk) and those with a first-degree (or two second-degree) relative with CRC (high risk) who were undergoing CRC screening as part of a population-based CRC screening program. We recorded their age at first screening, their reasons for screening and their self-perceived risks of CRC. This offers important information at the public health level on how well the screening guidelines are being applied and help to better inform resource needs for CRC screening.

The primary objective of the present study was to examine, in subjects undergoing CRC screening for the first time, the average age of persons at high risk for CRC (via a positive CRC family history) initiating CRC screening and the average age of persons at average risk for CRC (via no CRC family history) initiating CRC screening, relative to the recommended age for first-time CRC screening ( 40 years and 50 years, respectively). Secondary objectives were to determine whether the CRC screening was self-initiated or physician-initiated, reasons for screening and how accurately individuals perceived their risk for CRC relative to others.

\section{METHODS}

The present study was a cross-sectional analysis of first-time screening subjects enrolled into a pilot, population-based, comprehensive, integrated CRC screening program (Stop COlorectal cancer through Prevention and Education [SCOPE] Pilot) in Edmonton, Alberta. The SCOPE Pilot study population consisted of subjects in Northern Alberta who were referred by their family physician to a gastroenterologist for screening colonoscopy between April 2008 and October 2009. During that time, there was no organized population-based colon cancer screening program in Alberta. Based on family history (see definition below), both average- and high-risk subjects were included. Subjects were not required to have a positive fecal occult blood test to be included in the CRC screening program. Excluded were subjects with genetic CRC syndrome(s), on anticoagulation, pregnant, with a history of inflammatory bowel disease, significant gastrointestinal symptoms or other major medical problems, or were $<40$ years of age or $>75$ years of age. The SCOPE Pilot study nurses contacted the potentially eligible subjects via mail inviting the patient to participate in the study. Interested subjects attended an education session held at the University of Alberta Hospital (Edmonton, Alberta). Once consent was obtained, demographics, previous CRC screening history and detailed family history of CRC were acquired from the subjects via a self-administered questionnaire. The questionnaire was reviewed with the subject by the SCOPE study nurses. A positive family history was defined as a first-degree relative with CRC or adenomatous polyp (confirmed histologically) or two second-degree relatives with CRC. All participating subjects underwent three fecal occult blood tests and a colonoscopy by expert gastroenterologists.

Each first-time screening subject was then mailed a second questionnaire determining how their screening was initiated (ie, self-initiated versus physician-initiated), their reasons for screening, how they perceived and rated their own risk for CRC, and the highest level of education attended (below high school, completed high school, trade school, bachelor degree or postgraduate studies).

\section{RESULTS}

Of the 1260 subjects enrolled in the SCOPE Pilot program, 778 were identified as undergoing first-time CRC screening. Subject demographics are summarized in Table 1 . This group was then divided into those with a positive family history of CRC (see definition above) $(n=438[56.3 \%])$ and those without a family history of CRC $(\mathrm{n}=340[43.7 \%])$. The group with a positive CRC family history had a mean $( \pm$ SD) age for first-time screening of $54.4 \pm 8.5$ years (range 35 to 76 years of age). The group with no CRC family history had a mean age for first time screening of $58.2 \pm 6.4$ years (range 41 to 75 years of age). While those with a positive CRC family history initiated screening 3.8 years (95\% CI 2.8 to 4.8 years; $\mathrm{P}<0.05$ ) earlier than those without CRC family history, subjects with a positive CRC family history started their screening 14.4 years later than the recommended 40 years of age, and subjects with no CRC family history started their screening 8.2 years later than the recommended 50 years of age. Interestingly, the adenoma polyp detection rate for each group was found to be similar: $20.8 \%$ and $23.5 \%$ for the positive and negative family history groups, respectively.

The response rate for the second mailed questionnaire was $73.4 \%$ $(\mathrm{n}=571)$, in which $55.2 \%(\mathrm{n}=315)$ was from the positive CRC family history group and $44.8 \%(n=256)$ was from the no CRC family history group. How subject screening was initiated (ie, self-initiated versus physician-initiated), the subjects' reasons for screening, and how they perceived and rated their own risk of CRC was determined from the response of the 571 subjects. Patients who underwent colonoscopy as part of the SCOPE study, but did not respond to the questionnaire, were not included in the analysis

The majority of first-time CRC screening (outside the SCOPE program) was initiated by family physicians: $58.4 \%$ (184 of 315 ) for positive CRC family history and 66.7\% (170 of 255) for negative CRC family history (Figure 1). The second most common method of screening referral was by the subjects themselves through a self-initiated process. Subjects with a positive CRC family history were more likely to self-initiate their CRC screening (35.6\% [112 of 184]) than subjects without CRC family history (28.6\% [73 of 255]) (Figure 1).

Overall, study subjects underestimated their own risk of CRC (Figure 2). Only 43.8\% (Figure 2B, black bar, 135 of 308) of the positive CRC family history group rated their own risk appropriately in the above average-risk category, with $43.8 \%$ (Figure 2B, hatched bar, 135 of 308 ) and $12.4 \%$ (Figure 2B, open bar, 38 of 308) inappropriately rating their risk as average or below average, respectively. Conversely, $57.3 \%$ (Figure 2A, hatched bar, 141 of 246) in the negative CRC family history group rated their risk appropriately in the average-risk category, with $37.8 \%$ (Figure 2B, open bar, 93 of 255) inappropriately rating their risk as below average.

Five educational groupings were examined to determine whether the level of education altered the likelihood of individuals appropriately estimating their CRC risk (Table 2 and Figure 3). Subjects with other levels of education were added to the most similar of these five categories. The individual data are summarized in Table 2 and plotted in Figure 3. Figure 3A shows the subjects' own perceived risk of CRC for those with a positive CRC family history. In general, the subjects 


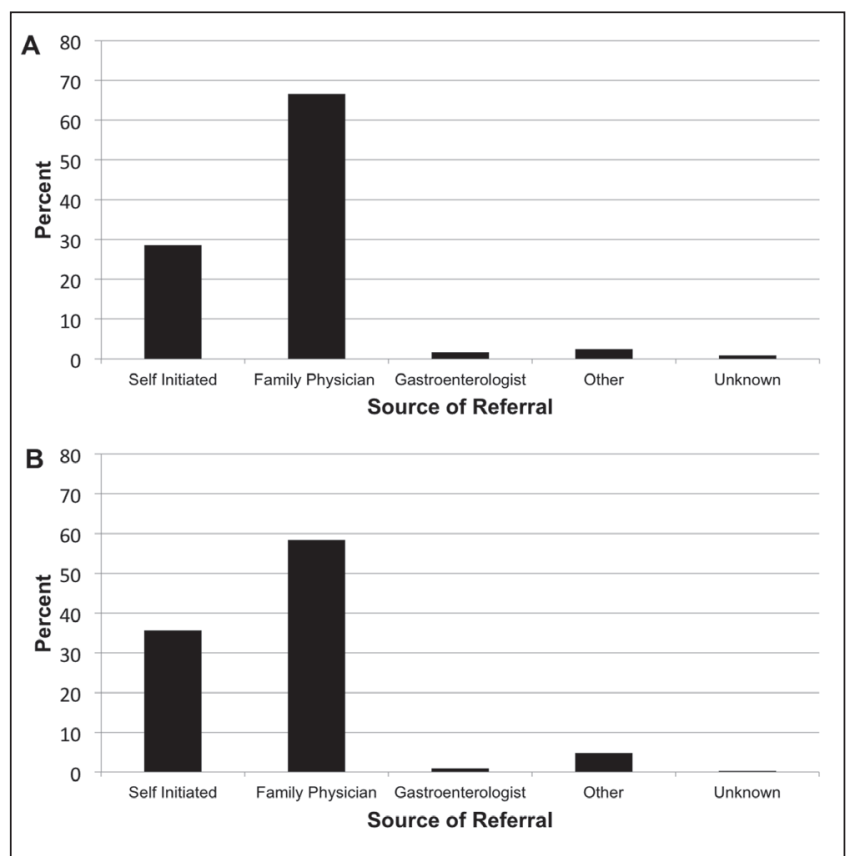

Figure 1) Source of referral for colorectal cancer (CRC) screening. A Negative family history of CRC. B Positive family history of CRC. Although more subjects self-initiated the process of screening themselves when having a positive family history of $\mathrm{CRC}$, the vast majority of each group was referred by their family physician

underestimated their CRC risk irrespective of education level attained; however, even in the group with the closest to correct risk perception, less than $50 \%$ appropriately estimated their CRC risk. Figure 3B shows the subjects' own perceived risk of CRC for those without CRC family history. In general, more individuals appropriately estimated the risk, irrespective of education level; however, again, less than 65\% appropriately estimated their CRC risk.

\section{DISCUSSION}

The findings of the present study demonstrate that first-time CRC screening, in a population-based CRC screening program, occurs a decade or more beyond the suggested age outlined in Canadian, American, European and Asian guidelines (5,9-11). This delay is seen in individuals with no CRC family history (approximately eight years beyond recommended screening at 50 years of age) as well as individuals with a CRC family history (approximately 14 years beyond recommended screening at 40 years of age). This delay in CRC screening imposes a needless risk for CRC-related morbidity and mortality. Many previous studies have demonstrated a low prevalence of CRC $(12-15)$ but our findings show, for the first time, that those who actually obtain first-time CRC screening are well beyond the optimal time to initiate screening to obtain the greatest benefit.

The clinical algorithm to CRC screening in the present study differs from that generally available in standard population-based CRC screening programs globally. These programs generally rely on a positive fecal occult blood test to precede colonoscopy. As part of the pilot screening program in Edmonton, all subjects underwent a colonoscopy, irrespective of the fecal occult blood status. Thus, the subjects in the present study were all aware they were getting a colonoscopy as part of their CRC screening. This may have biased those who entered; nevertheless, all patients entering a CRC screening program are aware that colonoscopy may be required. It should also be noted that this group is not representative of the general population in that they have presented for screening and due to the pilot study their colonoscopy wait times were dramatically reduced; therefore, the delay for screening may be even higher in the general public.

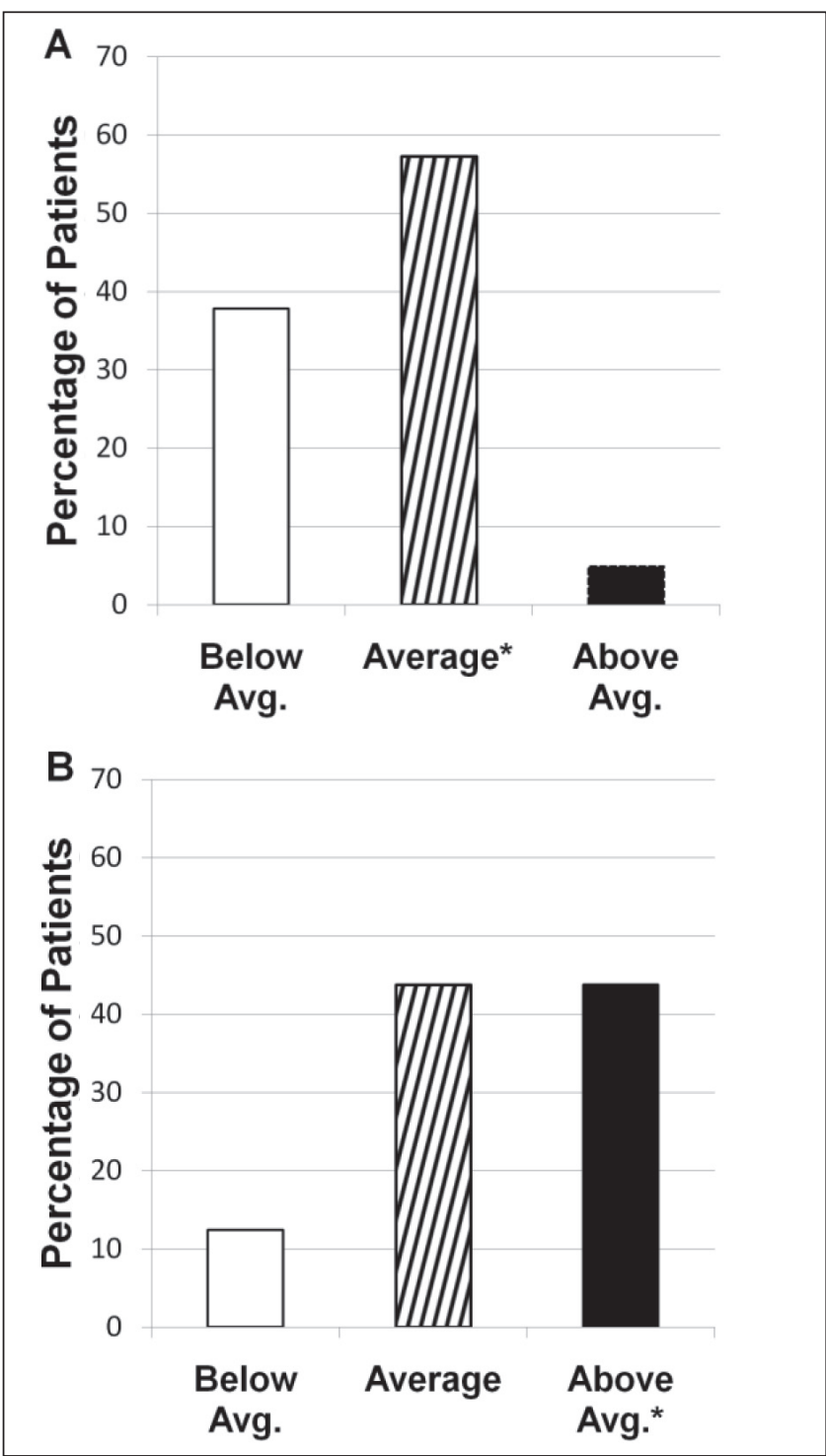

Figure 2) Subjects' personal risk of colorectal cancer (CRC). Individuals without a family history of $\mathrm{CRC}$ (A) perceive their risk for $\mathrm{CRC}$ better than those with a family history of CRC (B). *Denotes the appropriate risk category for each group. Avg Average

In both the CRC family history and nonfamily history groups, family physician recommendation was the single most significant factor in leading to first-time CRC screening, followed by a self-initiated referral (Figure 1). In general, in this pilot screening program, the self-initiated referral would require a family physician assessment and referral into the program. The fact that the family physician is the 'gatekeeper' for CRC screening and the strongest predictor of screening compliance indicates that resources and knowledge transfer for population-based CRC programs will need to be focused at this point in the clinical pathway.

Indeed, in the present study, a large percentage of subjects underestimated their risk of CRC, irrespective of whether they had a CRC family history. Wee et al (12) identified that much of the low prevalence of screening is due to lack of subject awareness of the benefits of screening from inadequate health care and physician counselling. Wee et al (12) and McGregor et al (16) also suggested that physicians do not discuss screening with more than one-half of eligible subjects.

Another surprising finding was how many individuals believed that they were at a lower risk for CRC than they actually were (Figure 2). The results of the present study were similar to those reported in women who underestimated their risk of death from CRC (17). Also 
TABLE 2

Assessment of personal risk for colorectal cancer (CRC) according to educational level: inappropriately estimated versus appropriately estimated

\begin{tabular}{|c|c|c|}
\hline \multirow[b]{2}{*}{ Highest education level attained } & \multicolumn{2}{|c|}{ Family history of CRC } \\
\hline & Positive, n/n (subjects' perceived risk of CRC, \%) & Negative, n/n (subjects' perceived risk of CRC, \%) \\
\hline \multirow[t]{2}{*}{ Not completed high school $(n=21)$} & Below: 6/10 (60) & Below: 1/11 (9.1) \\
\hline & Appropriate: 4/10 (40) & Appropriate: 10/11 (90.9) \\
\hline \multirow[t]{2}{*}{ Completed high school $(n=116)$} & Below: 32/62 (51.6) & Below: 25/54 (46.3) \\
\hline & Appropriate: 30/62 (48.4) & Appropriate: 29/54 (53.7) \\
\hline \multirow[t]{2}{*}{ Trade school $(n=196)$} & Below: 66/112 (58.9) & Below: 41/84 (48.8) \\
\hline & Appropriate: 46/112 (41.1) & Appropriate: $43 / 84$ (51.2) \\
\hline \multirow[t]{2}{*}{ Bachelor program $(n=127)$} & Below: 35/68 (51.5) & Below: 23/49 (46.9) \\
\hline & Appropriate: 33/68 (48.5) & Appropriate: 26/49 (53.1) \\
\hline \multirow[t]{2}{*}{ Graduate program $(n=99)$} & Below: 32/52 (61.5) & Below: 15/47 (31.9) \\
\hline & Appropriate: 20/52 (38.5) & Appropriate: 32/47 (68.1) \\
\hline
\end{tabular}
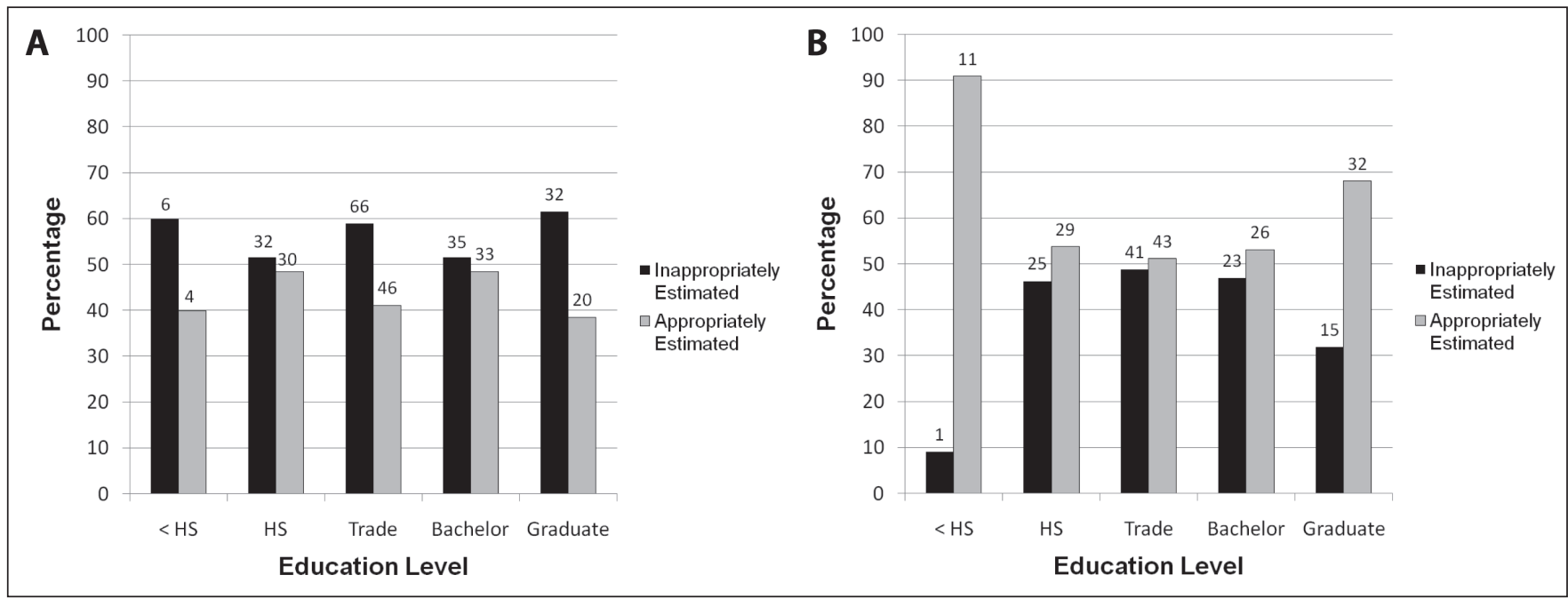

Figure 3) A Education level and subjects' perceived risk of colorectal cancer (CRC) for individuals with a positive CRC family history. Inappropriately estimated included those subjects who ranked their risk or CRC as below average or average. Appropriately estimated includes those subjects who ranked their risk of $\mathrm{CRC}$ as above average risk. It is shown that no matter the education level of the subject, the majority will inappropriately estimate their risk of CRC if they have a positive family history. B Education level and subjects' perceived risk of CRC for individuals with a negative family history of CRC. Inappropriately estimated included those subjects who ranked their risk of $\mathrm{CRC}$ as below average or above average. Appropriately estimated included those subjects who ranked their risk of $\mathrm{CRC}$ as average risk. It is shown that no matter the education level of the subject, the majority will appropriately estimate their risk of CRC if they have a negative family history. Values above each bar the are number of subjects in each group. <HS Less than high school education; HS High school education

surprising was the fact that all of the subjects in the present study had completed a $2 \mathrm{~h}$ face-to-face CRC screening lecture symposium that outlined the dangers of CRC and the benefits of early screening. These misunderstandings need to be addressed by physicians, health care workers and knowledge transfer through population-based colon cancer screening programs. A study examining the effect of a mailed video about CRC and the importance of early screening on CRC screening rates (18) demonstrated that it has little effect on the overall rate of CRC screening, strengthening the need for patient education that is accepted and incorporated by the population.

It is important to note that each of the patients surveyed were aware of their colonoscopy results and had received the SCOPE education program. Thus, the findings on perceived risk may be influenced by the knowledge gained and the results. Furthermore, the general applicability of the data must be interpreted given the fact that the positive family history group included those with both CRC as well as adenomatous polyps (see Methods), in contrast to most populationbased guidelines for colon cancer screening that include only family of subjects with CRC and not family history of adenomatous polyps.

Education level attained had little impact on a subject's perceived risk of CRC. However, again, the majority underestimated their own CRC risk, particularly those with a positive CRC family history, who were more likely to underestimate CRC risk than those with no CRC family history (19-21). This raises the question of where we should put our educational intervention dollars: in educating the population about screening guidelines and CRC risk, or in educating the family physician.

\section{SUMMARY}

Individuals with a positive CRC family history are initiating CRC screening approximately four years earlier than those with no CRC family history; nevertheless, both groups are initiating their first screening nearly a decade beyond the optimal age suggested by current guidelines. Adenoma detection rates at colonoscopy were similar in both groups. Furthermore, the majority of subjects, irrespective of education level attained, did not appropriately recognize their own CRC risk.

ACKNOWLEDGEMENTS: Funding for this project was provided through Alberta Health Services, The University Hospital Foundation and The Center of Excellence for Gastrointestinal Inflammation and Immunity Research. The authors also thank the SCOPE Pilot staff: Linda Hickle, Twyla Fletcher, Carmen Weaver and Colleen McKee, for their work in patient recruitment. 


\section{REFERENCES}

1. Canadian Cancer Society. Colorectal cancer statistics at a glance. $<$ www.cancer.ca/Alberta-NWT/About cancer/Cancer statistics/Stats at a glance/Colorectal cancer.aspx?sc_lang=en\&r=1> (Accessed May 27, 2011).

2. National Cancer Institute. Colon and Rectal Cancer. 2010. $<$ www.cancer.gov/cancertopics/types/colon-and-rectal> (Accessed June 23, 2010).

3. Rees G, Martin PR, Macrae FA. Screening participation in individuals with a family history of colorectal cancer: A review. Eur J Cancer Care 2008; 17:221-32.

4. Sewitch MJ, Fournier C, Ciampi A, Dyachenko A. Colorectal cancer screening in Canada: Results of a national survey. Chronic Dis Can 2008;29:9-21.

5. Leddin D, Hunt R, Champion M, et al. Canadian Association of Gatroenterology and the Canadian Digestive Health Foundation: Guidelines on colon cancer screening. Can J Gastroenterol 2004;18:93-9.

6. Rex D, Johnson D, Anderson J, Schoenfelld P, Burke C, Inadomi J. American College of Gastroenterology guidelines for colorectal cancer screening 2008. Am J Gastroenterol 2009;104:739-50.

7. Mack LA, Cook LS, Temple WJ, Carlson LE, Hilsden RJ, Paolucci EO. Colorectal cancer screening among first-degree relatives of colorectal cancer patients: Benefits and barriers. Ann Surg Oncol 2009;16:2092-100.

8. Fletcher RH, Lobb R, Bauer MR, et al. Screening subjects with a family history of colorectal cancer. J Gen Intern Med 2007;22:508-13.

9. Rex DK, Johnson DA, Anderson JC, Schoenfeld PS, Burke CA, Inadomi JM. American College of Gastroenterology Guidelines for Colorectal Cancer Screening 2008. Am J Gastroenterol advance online publication, 24 February 2009.

10. Segnan N, Patnick J, von Karsa L, et al. European guidelines for quality assurance in colorectal cancer screening and diagnosis. Luxemburg: Publications Office of the European Union, 2010.
11. Sung JJY, Lau JYW, Young GP, et al. Asia Pacific consensus recommendations for colorectal cancer screening. Gut 2008;57:1166-76.

12. Wee CC, McCarthy EP, Phillips RS. Factors associated with colon cancer screening: The role of patient factors and physician counselling. Prev Med 2005;41:23-9.

13. Centers for Disease Control and Prevention. Trends in screening for colorectal cancer-United States, 1997 and 1999. Morb Mortal Wkly Rep 2001;50:162-80.

14. Walsh JM, Posner SF, Perez-Stable EJ. Colon cancer screening in the ambulatory setting. Prev Med 2002;35:209-18.

15. Vernon SW. Participation in colorectal screening: A review. J Natl Cancer Inst 1997;89:1406-22.

16. McGregor SE, Hilsden RJ, Li FX, Bryant HE, Murray A. Low uptake of colorectal cancer screening $3 \mathrm{yr}$ after release of national recommendations for screening. Am J Gastroenterol 2007;102:1727-35.

17. Wilcox S, Stefanick ML. Knowledge and perceived risk of major diseases in middle-aged and older women. Health Psychol 1999; 18:346-53.

18. Zapka JG, Lemon SC, Puleo E, Estabrook A, Luckman R, Erban S. Patient education for colon cancer screening: A randomized trial of a video mailed before a physical examination. Ann Intern Med 2004;141:683-92.

19. Safaee A, Moghimi-Dehkordi B, Pourhoseingholi MA, et al. Risk of colorectal cancer in relatives: A case control study. Indian J Cancer 2010;47:27-30.

20. Fatemi SR, Malek FN, Shivarani S, et al. Prevalence of colorectal cancer in relatives of Iranian patients diagnosed with colorectal cancer. Asian Pacific J Cancer Prev 2010;10:91-3.

21. McGregor SE, Bryant HE. Predictors of colorectal cancer screening: A comparison of men and women. Can J Gastroenterol 2005;19:343-9. 


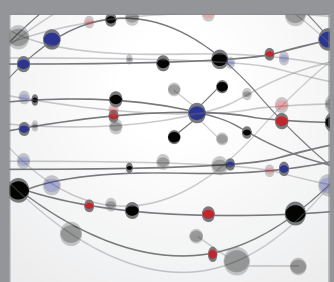

The Scientific World Journal
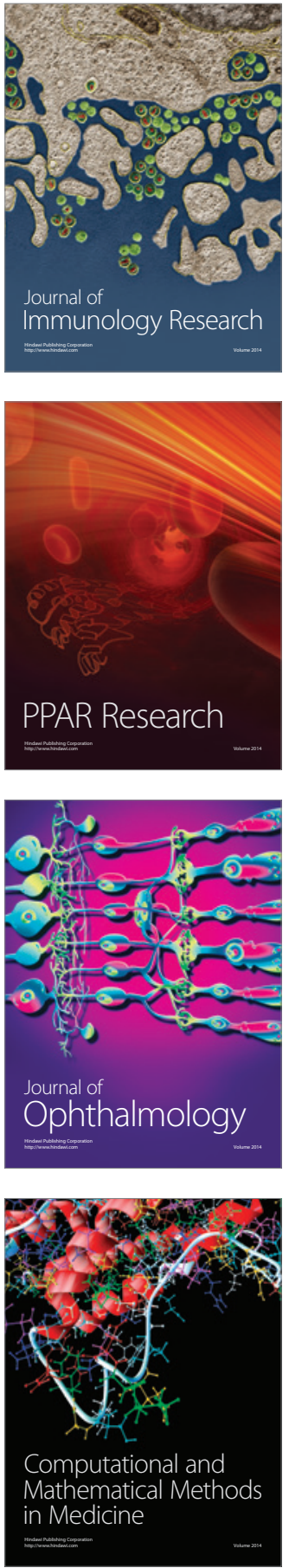

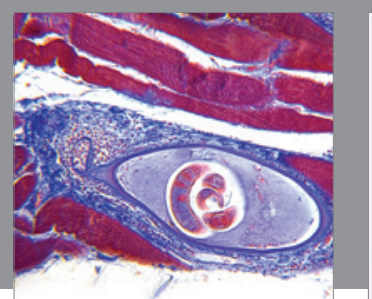

Gastroenterology Research and Practice

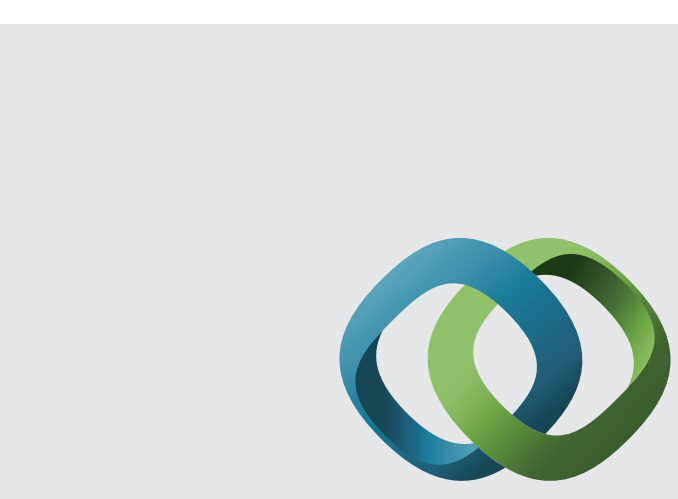

\section{Hindawi}

Submit your manuscripts at

http://www.hindawi.com
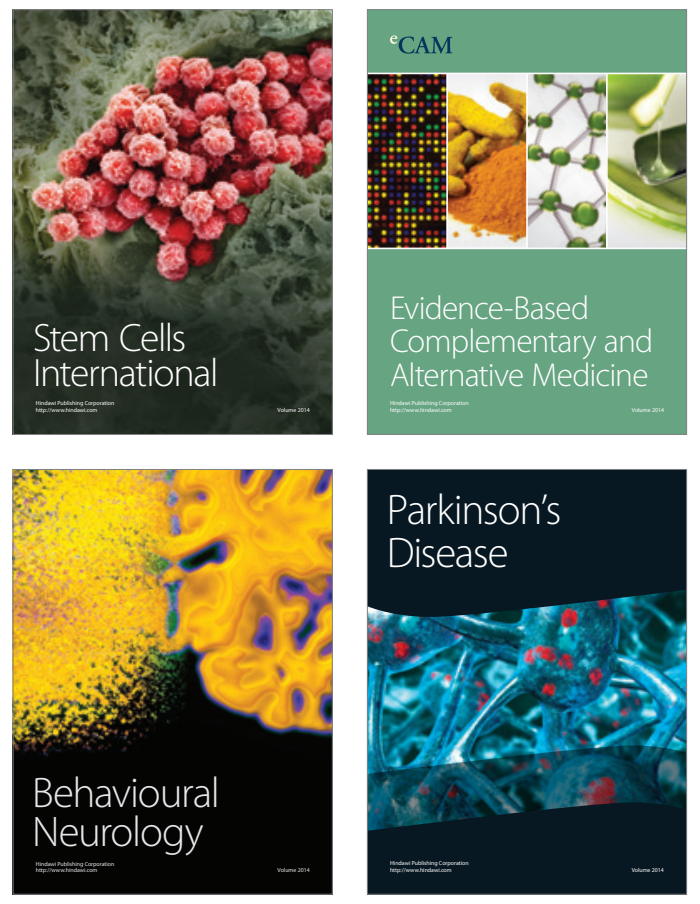
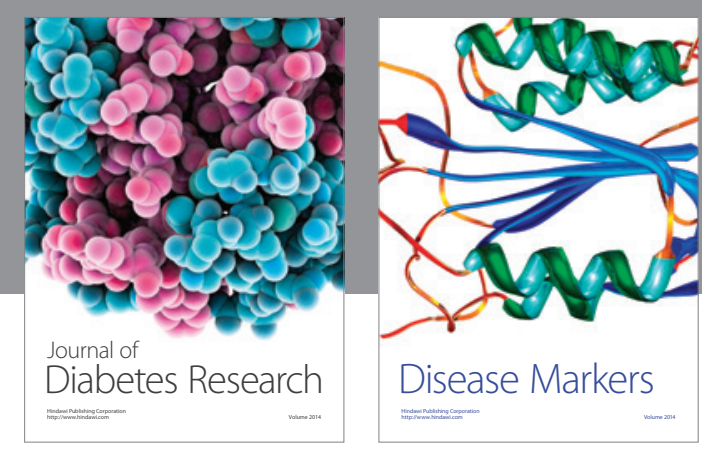

Disease Markers
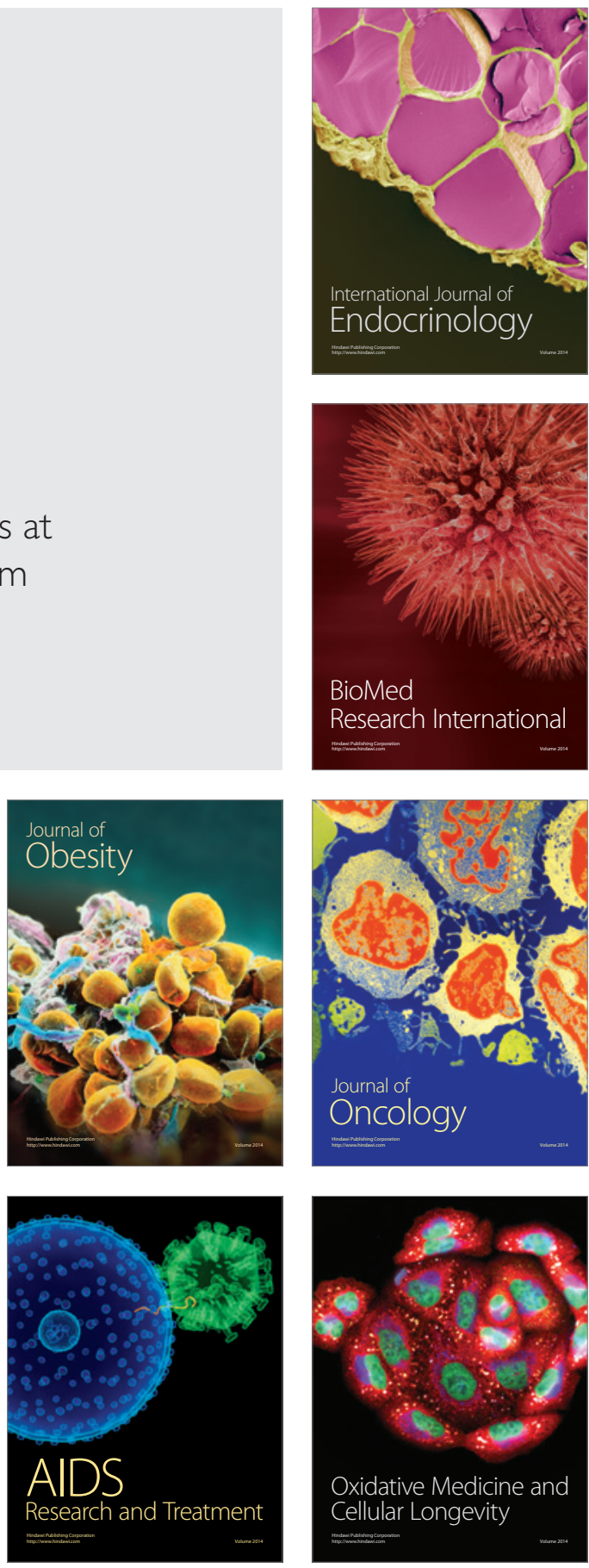